\title{
Critics of Delegation and Decentralization in Abdicating Authority and Upholding Ubuntu Philosophy in Social Welfare Organizations
}

\author{
Tariro Portia Tendengu \\ Zimbabwe Ezekiel Guti University, Bindura, Zimbabwe \\ Email: portiatendengu@gmail.com
}

How to cite this paper: Tendengu, T. P. (2021). Critics of Delegation and Decentralization in Abdicating Authority and Upholding Ubuntu Philosophy in Social Welfare Organizations. Advances in Anthropology, 11, 249-259.

https://doi.org/10.4236/aa.2021.113014

Received: July 10, 2021

Accepted: August 28, 2021

Published: August 31, 2021

Copyright $\odot 2021$ by author(s) and ScientificResearch Publishing Inc.

This work is licensed under the CreativeCommons Attribution International

License (CC BY 4.0).

http://creativecommons.org/licenses/by/4.0/

\section{(c) (i) Open Access}

\begin{abstract}
The purpose of this paper is to reach the augment of the critics of delegation and decentralization in abducting authority and upholding Ubuntu philosophy in Social Welfare Organizations in Zimbabwe. The systematic distribution of authority by the top management in social welfare organizations remains a contested issue in abdicating authority and upholding Ubuntu Philosophy. Abdicating respect and human dignity in delegating responsibility is one of the critical issues in social welfare organizations as some community-based organizations fail to consider the inherent worth of employees before conducting some projects and allocating tasks. In governmental parastatals participatory democratic values are not effectively implemented when delegating duties, the top management restricts itself to major decisions areas like policymaking, coordination and control. The lower-level managers have enough decision-making authority and support to introduce innovativeness in their work. A desktop review was used in accordance with the case study for the study, qualitative and qualitative research methods were used to gather data collected from the research. Data collection methods that were used included observations, focus group discussions and interviews. The targeted population included international, statutory and non-statutory organizations in Zimbabwe. Findings from the study concluded that delegation and decentralization in social welfare organizations are criticized as a result of local beurocracy and inequalities that exist in organizations. Respondents articulated that decentralization becomes an important handicap in upholding the organizational values and ethics. In social welfare organizations, some executives do not understand the basic need for basic respect and compassion for other employees like sharing the responsibility of decision-making.
\end{abstract}

\section{Keywords}

Delegation, Decentralization, Authority, Ubuntu Philosophy, 


\section{Definition of Terms}

\subsection{Authority}

(Stonner et al., 2003) espoused that authority is a legal or rightful power, a right to command or to act. Stonner further argues that authority is to command or order as well as to delegate from the supervisor to the subordinate to discharge his responsibilities. (Yalokwu, 2006) defined power as the capacity or ability to influence the behavior of other individuals or subordinates. One of the hallmarks of great leadership is effective delegation. (Robbins \& Coulter, 2007) defines delegation as, to give a task to somebody else with the responsibility to act on your behalf. That is to give somebody else the power to act, make decisions or allocate resources on your behalf. According to (Robbins, 2009) delegation is when a manager assigns some part of his work to his subordinates and grand them the necessary authority to make decisions.

\subsection{Decentralization}

(Robbins \& Coulter, 2007) espoused that decentralization refers to the systematic effort to delegate to the lower levels of all authority that can only be exercised at control points. To abdicate, on the other hand, is simply to fail to fulfill a duty or responsibility. The word abdication is derived from the Latin abdication meaning to disown or renounce (Stonner et al., 2003). In a broader sense abdication is the act of renouncing and resigning from any office but it is applied especially to the supreme office of state. According to (Robbins \& Coulter, 2007) decentralization is both a philosophy of management (to prepare inside people for future positions) and a technique of organizing (creating a number of centers of initiative). (Stonner et al., 2003) argues that decentralization of authority is different from the dispersal of activities. Thus dispersal of activities in different geographical areas is a strategic decision; decentralization is concerned with the distribution of authority, not the activities. (Stonner et al., 2003) further argues that decentralization is an extension of delegation: there may be delegation without decentralization, but no decentralization is possible without delegation. The degree of decentralization can be measured through a number of decisions, more important decisions, the scope of decisions, and less controls on lower-level managers.

\section{Rationality of the Study}

Research studies relating to the Ubuntu Philosophy mainly focus on issues relating to the Ubuntu perspective in African contemporary societies. Issues relating to the critics of delegation and decentralization in abdicating authority and upholding Ubuntu Philosophy has been overlooked in as far as research on 
Ubuntu philosophy is concerned, in regard to this the researcher is to fill this research gap by considering the critic of delegation and decentralization in abdicating authority and upholding Ubuntu philosophy in Social Welfare Organizations. This study will therefore form the genesis of effective practice in social welfare organizations.

\section{Literature Review}

\subsection{Applicability of Delegation in the Child and Adult Welfare System and Upholding Ubuntu Philosophy}

The capacity and the ability to make strategic decisions and the confidence to follow through with these decisions are two qualities commonly ascribed to welfare organizational leaders (Ridgeway \& Becker, 1986). The decisions made within organizations can range from these "big picture" decisions through to small incremental decisions that occur in the everyday life of the organization and this depends with the situations that are being responded to. Surprisingly, modern day Social Work with children does not seem to acknowledge fully the potential of Ubuntu to inform perspectives, theories and models that social welfare organizations use in professional practice (Rankopo \& Osei-Hwedie, 2011). Similarly (Mugumbate \& Chereni, 2019) observed that, Mbiti's view of Ubuntu Philosophy, often termed the African view of men says, "What happens to the individual happens to the whole group and whatever happens to the whole group happens to the individual." Not all tasks however need to be carried out by a manager due to high work load and other commitments within the organization.

The applicability of delegation and Ubuntu philosophy in the child and adult welfare can be understood through decentralization though they are two different concepts. This can be supported by (Metz, 2016) anti-poverty and social protection model of Ubuntu, in this model the author views Ubuntu as a social protection and anti-poverty framework. Ubuntu as augmented by (Metz, 2016) is a mechanism that provides a social safety net in welfare organisation for individuals through family support, community support or societal support as a whole (Mugumbate \& Chereni, 2020). If everything could be centralized and done at the top management, inefficiency would be the order of the day in the welfare organizations. In Zimbabwe were resources seem and reported to be scarce, the backload of work is high and there is a need to delegate some tasks to lower level personnel.

Decentralization and delegation are healthy practices in the management of social welfare organizations. Their benefits to the successfulness of an organization make them applicable in the management of child and adult welfare organizations. It can be noted that, there is a need for highly qualified subordinates for these concepts to be applicable. The top management should be rest assured and convinced that its subordinates will be able to deliver as expected. Other issues to be considered are the urgency and the importance of work that is to be delegated and the decisions that are to be decentralized. This assists in when and to whom should this happen for good results. 


\subsection{Delegation and Decentralization in Recognizing Employee's Cultural Values in Social Welfare Organizations}

The manager can use the above theories and the $\mathrm{ABC}$ method of setting priorities to the effectiveness of the organization. According to the $\mathrm{ABC}$ method of setting priorities, there are tasks that also determine when delegation is appropriate. These priorities fall under three categories, category " $\mathrm{A}$ " consist of very important tasks with serious consequences if you do or fail to do them... These tasks should be done by managers and not delegated. If the manager has so many A's he/she should prioritise the tasks to A-1, A-2, A-3 and so on. A-1 being the biggest tasks and require attention. The manager then decides on the secondary tasks as the second category. These are tasks which a manager does but have mild consequences. These are not as important as the tasks in category "A". This can be delegated if the manager has so many " $\mathrm{A}$ "s. The last category is "C", it consists of tasks that one should do but may not have any consequences.

An example can be given in relation to the Zimbabwean context, the Director of Department of Social Welfare and Protection Services delegate responsibility to his provincial officers. Although the director assigns responsibility to the provincial officers, he/she will still be accountable for the delegated work. Delegation does not entail a simple task that may be assigned to the whim of the manager. In line with the afore-mentioned definitions when a manager requires subordinates to bring him or her a cup of coffee, it is an errand not delegated work. Neither is getting the company car serviced and calling a client to tell him/her that the manager will be late for the appointment. These are just tasks that a manager may ask a subordinate to perform from time to time but do not qualify as delegation of work related task. Despite these routines simplifying a manager's life, one should avoid or cast aside such broad set of tasks and contribute or focus on tasks that lead to the organization reaching its goal.

\subsection{Principle Guidance on How to Delegate}

Principle of result expected emphasizes that before delegation of authority to subordinates, the manager should know the purpose of the delegation process and the results that are expected from it. The manager should delegate broadly identifying levels of empowerment from lower to high level. The subordinate should clearly understand the goal or target and standard performance of the delegated work. Taking for example at the Department of child welfare and protection services, the child welfare officer as lower management can delegate work to his/her subordinates (interns) to write probation officers report to the court for renewal of placement orders or inquiring a new order. The manager guided by this principle should ensure that the subordinate understands how to conduct assessment, the goal of the assessment process and how to develop a report. Guided by the principle, it determines the authority to be delegated which is sufficient for completing the responsibility. This reduces burden on the superior taking into consideration the heavy work load at the Department of Child Welfare and Protection Services (Harare Central District) were Child Welfare Officers are overloaded 
with work. This ensures effectiveness of an organization as the superior/manager will focus his/her attention to other issues, but still getting feedback from the subordinates on the tasks. (Ahmed \& Jensen, 2009) supports this saying, although he/she assigns responsibilities to the subordinates, the managers will still be accountable for the delegated work.

Maslow's hierarchy of needs elucidate on motivation of people in meeting their needs. Paying particular attention to his elaboration on esteem needs, people want to be recognized and respected for their accomplishments. Delegating responsibility and authority creates a platform to which individuals/subordinates would want to utilize to achieve their goals and be recognized. This brings to our mind the delegation principle of parity of authority and responsibility which states that if subordinates are assigned certain responsibilities they must be given some level of authority or power to effectively perform their responsibility. Through clear understanding of the responsibility and authority he has, the subordinate will also understand what is required of him, within the power delegated to him. This reveals the fundamental nature of delegation in managing organizations as delegating additional responsibilities to subordinates will provide a platform for self-satisfaction, achievement and gain recognition. This brings into question how managers should delegate, the amount of authority needed for the job must be given to the employee so that they can feel there is a sense of self-determination in their work. They must also be held accountable for the work results that they produce. Relating to the afore-said example, the Child welfare officer as lower management in the Department of child welfare and protection services may give/ assign subordinates to more challenging task like adoption cases or juvenile delinquency cases. This challenges subordinates or interns to be more analytical and apply their skills because these are highly sensitive cases. The subordinate may better understand issues on the ground than the manager, putting him in a best position to make appropriate and effective decisions. Therefore authority should be delegated along with the responsibility, on behalf of his superior. Professional development is accelerated and also effectiveness of the organization as a whole. The subordinate is given adequate authority and responsibility to solve the cases on his own, this increases motivation towards higher achievement. This increases responsiveness when responsibilities are delegated to lower practical levels ensuring quick effectiveness in response to innumerable situations. Although the principle of absolute responsibility states that even after authority being delegated to the subordinate, the manager will be answerable for the actions/decisions the subordinate makes. The responsibility is absolute and still remains with the superior.

\section{Ubuntu Philosophy}

\subsection{The Ubuntu Approach}

The first one is that to be human is to affirm one's humanity by recognizing the humanity of others and, on that basis, establish respectful human relations with 
them. Thus, a person is who he is because of what other people are; umuntungomuntungabantu. One cannot say that he/she is human if he/she does not understand the humanity of other people. The second maxim is that if and when one is faced with a decisive choice between wealth and the preservation of the life of another human being, then one should choose the preservation of life. This implies that one should not value profit making more than the well-being of others, which is well opposed o the notions of the other approaches such as the modernization and the Developmentalist approach. As a principle deeply embedded in traditional African political philosophy, the king owed his status to the will of the people under him. Thus, his power was in his subjects, he could not impose anything on them. They had to agree on every decision that had to be made concerning the community as a whole.

Human worth is based on social, cultural and spiritual criteria and competence rather than conventional market-based conceptions. Natural resources are shared on principle of equity among and between generations. This just emphasizes the notion of communal ownership of land, mutualism and generosity.

\subsection{Critique of the Ubuntu Approach}

The Ubuntu philosophy does not mean that people should not address themselves to a problem, but it does imply that they should look at whether what they are doing will enable or empower the community around them and help it improve. The Ubuntu philosophy also implies that if people are treated well, they are likely to perform better. Criticism of ubuntu is its apparent collectivist orientation, with many suspecting that it requires some kind of group-think, uncompromising majoritarianism or extreme sacrifice for society, which is incompatible with the value of individual freedom that is among the most promising ideals in the liberal tradition. Here, again, self-described adherents to ubuntu have done little to dispel such concerns, for example, an author of an important account of how to apply ubuntu to public policy remarks that it entails "the supreme value of society, the primary importance of social or communal interests, obligations and duties over and above the rights of the individual". A third ground of scepticism about the relevance of ubuntu for public morality is that it is inappropriate for the new South Africa because of its traditional origin. Ideas associated with ubuntu grew out of small-scale, pastoral societies in the pre-colonial era whose world views were based

\section{Delegation and Decentralization in Management of Social Welfare Organizations}

Delegation and decentralization in management of social welfare organizations have been criticized as abdicating of authority does not promote growth among staff members, innovation as well as knowledge sharing across different entities of the organization. This reveals the fundamental nature of delegation in managing organizations as delegating additional responsibilities to subordinates will 
provide a platform for self-satisfaction, achievement and gain recognition. According to (Robbins \& Coulter, 2007) decentralization leads to delegation of authorities in large amount thus a person with right authority is compelled to contour plate or to do something new. This inculcates in him the ability to take the initiative. (Ali, 2014) asserts that decentralization and delegation provides the opportunity to take decisions adds to the knowledge and experience of managers at all levels and develops talent to bear extra responsibility in future. This brings into question how managers should delegate, the amount of authority needed for the job must be given to the employee so that they can feel there is a sense of self-determination in their work. They must also be held accountable for the work results that they produce. Relating to the afore-said example, the Child welfare officer as lower management in the Department of child welfare and protection services may give/assign subordinates to more challenging task like adoption cases or juvenile delinquency cases. This challenges subordinates or interns to be more analytical and apply their skills because these are highly sensitive cases. The subordinate may better understand issues on the ground than the manager, putting him in a best position to make appropriate and effective decisions. Therefore authority should be delegated along with the responsibility.

\section{Ubuntu Philosophy in Abdicating and Delegating Authority in Social Welfare Organizations}

It can be contested that, upholding the Ubuntu philosophy in abdicating and delegating authority in social welfare organizations is a challenge as in some organizations principles of humanity and respect are not considered when delegating authority. For example delineating delegation and decentralization of power from abdication the senior member remains responsible and accountable of the junior member's actions while in abdication the senior members relinquishes his or her responsibilities and is not accountable of the junior member's actions. Hence it is clear that (Ali, 2014) further argues that in a decentralized organization, the burden of managerial decisions does not lie on a few individuals but it is distributed among many people with complete knowledge about their units or departments. It is of paramount importance to note that unlike abdication, decentralization leads to quick as well as better decision making, it also fosters a notion of shared responsibilities among staff members which is alien in the lands of abdication. (Robbins \& Coulter, 2007) asserts that, unlike abdication decentralization makes it possible to evaluate performance at each level and departments can be individually held accountable for their performances. In tandem with this abdication can lead to disastrous results. Tasks aren't completed properly or at all, you have unhappy customers, missed deadlines, financial problems.

(Robbins \& Coulter, 2007) asserts that delegation is the transfer of authority from superior to subordinate and it is build on three elements which are authority, responsibility and accountability. While authority is delegated, responsibility is assumed, accountability is imposed. Responsibility is derived from authority 
and accountability is derived from responsibility. (Ryan, 2014) defines authority as the power legitimized by the organization which empowers a manager to make decisions, to use organizational resources, and to monitor and regulate the behavior of subordinates for the efficient performance of assigned work responsibilities. Authority is positional and can be delegated. According to (Olum, 2004) the principle of result expected suggests that every manager before delegating the powers to the subordinate should be able to clearly define the goals as well as results expected from them. (Olum, 2004) further argues that the goals and targets should be completely and clearly defined and the standards of performance should also be notified clearly. (Robbins, 2009) espoused that delegation of authority requires a manager to uphold the principle of Parity of Authority and Responsibility. According to this principle, the manager should keep a balance between authority and responsibility. In tandem with this the subordinate and the manager must go hand in hand. (Robbins, 2009) also notes that if a subordinate is given a responsibility to perform a task, then at the same time he should be given enough independence and power to carry out that task effectively. Thus unlike abdication, delegation does not provide excessive authority to the subordinate which at times can be misused by him. The authority should be given in such a way which matches the task given to him. Therefore, there should be no degree of disparity between the two.

(Stonner et al., 2003) asserts that it is common in abdication that there is a total shift of responsibilities to the subordinate and this mark a difference with delegation of authority. Thus authority can be delegated but responsibility cannot be delegated by managers to his subordinates which mean responsibility is fixed. (Stonner et al., 2003) further argues that the manager at every level, no matter what is his authority, is always responsible to his superior for carrying out his task by delegating the powers. That is, every superior is responsible for the acts of their subordinates and are accountable to their superior therefore the superiors cannot pass the blame to the subordinates even if he has delegated certain powers to subordinates. For instance, if the production manager has been given a work and the machine break down. If repairman is not able to get repair work done, production manager will be responsible to $\mathrm{CEO}$ if their production is not completed. (Olum, 2004) notes that, in abdication of authority there are no clear boundaries whilst in delegation the exercise of authority lies within the stipulated jurisdiction or framework given. The manager is forced to consult his or her superiors with those matters of which the authority is not given that means before a manager takes any important decision, he should make sure that he has the authority to do that on the other hand, subordinate should also not frequently go with regards to their complaints as well as suggestions to their superior if they are not asked to do.

On the contrary, (Robbins, 2009) notes that one of the biggest barriers to delegation is that managers do not have enough time to either adequately explain the task or teach staff members the skills necessary for a delegated task. This is also typical in abdication of authority hence bringing to light that delegation of 
authority and abdication may equally bring inertia among staff members or it may lead to the organization producing sub-standard products. Abdication and decentralization depends upon the decision made by the enterprise, it is not compulsory. Thus decentralization is an optional policy at the discretion of top management.

\section{Methodology}

A desktop review was used in accordance with the case study for the study, qualitative and qualitative research methods were used to gather data collected from the research. Data collection methods that were used included observations, focus group discussions and interviews. The targeted population included international, statutory and non-statutory organizations.

\subsection{Target Population}

The targeted population included international, statutory and non-statutory organizations.

\subsection{Data Collection Methods}

\subsubsection{Documentary Research}

The researcher also studied documents with information that could provide insight into the phenomena under investigation.

\subsubsection{Observations}

(D'Cruz \& Jones, 2004) argue that observation is an active process where knowledge is negotiated and generated in interactions between the researcher and the participants/respondents. Observation constituted an important part of data gathering.

\subsubsection{Recording and Note Taking}

According to (Rubin \& Babbie, 2011: p. 470), "the aims and philosophical roots of qualitative inquiry mandate that the respondent's answers should be recorded as fully as possible." Since verbatim recording is ideal, electronic recording is a powerful tool for the researcher. The authors further note it "ensures verbatim recording,...frees interviewers to keep full attention focused on respondents, communicates that they are listening to what is being said and to probe into important cues" (ibid). The researcher used mobile telephones and audio recorders to capture verbatim accounts of interviews and discussions.

According to (Saunders et al., 2009), in addition to audio recording interviews, it is also important to take notes as interviews and discussions progress. This allows the researcher to evaluate the adequacy of his/her interpretation and correct where necessary, to corroborate with the respondent to test the validity of interpretations as well as to add any further points that may have been missed (ibid). (Rubin \& Babbie, 2011) advise interviewers to record immediately the full details of the interview and other contextual data (i.e. location of interview, date and 
time, setting, background information, impressions of the conduct of the interview/discussion). The researcher sought permission to record and take notes from participants during surveys, in-depth interviews and focus group discussions. The relevant ethics surrounding recording participants and respondents were observed.

\section{Findings}

The findings from the study concluded that, social welfare organizations in Zimbabwe exist to fulfill some human values, for example; human rights, citizen responsibility, social justice and equity. However it can be argued that, most organizations, be it governmental, intergovernmental or nongovernmental are highbreed organizations that embrace the Ubuntu Philosophy in decentralizing and delegating duties and responsibilities. These organizations are more often than not influenced by national or international politics. Managers therefore are faced with a dilemma of having to negotiate between serving the actual needs of their clients at the same time fulfilling the mandate set by politics.

\section{Recommendations}

- Management practices and policies should consider organizational culture, leadership styles employees' social value and corporate social responsibility.

- The Ubuntu Philosophy should be offered as a module in social welfare organizations.

- Organizations in African contemporary societies should implement strategies which allow team work centered on the Ubuntu Philosophy.

- Social Welfare organizations should juxtapose delegation principles and the Ubuntu Philosophy.

\section{Conclusion}

In social welfare organizations, sub-ordinates should not receive multiple instructions of duties because it undermines authority, weakens discipline, divides loyalty, creates confusion, delays and chaos, escaping of responsibilities, duplication of work, and overlapping of efforts. Dual subordination should be avoided until it is essential because it is believed that the organization is disciplined enough to have the right people in the right positions.

\section{Conflicts of Interest}

The author declares no conflicts of interest regarding the publication of this paper.

\section{References}

Ahmed, N., \& Jensen, C. (2009). A Mechanism for Identity Delegation at Authentication Level. 2009 Nordic Conference on Secure IT Systems, Oslo, 14-16 October 2009, 148-162. https://doi.org/10.1007/978-3-642-04766-4 11 
Ali, A. (2014). Management Theory and Practice.

D’Cruz, H., \& Jones, M. (2014). Social Work Research in Practice: Ethical and Political Context (2nd ed.). SAGE Publications Ltd. https://doi.org/10.4135/9781446294963

Metz, T. (2016) Recent Philosophical Approaches to Social Protection: From Capability to Ubuntu. Global Social Policy, 16, 132-150.

https://doi.org/10.1177\%2F1468018116633575

Mugumbate, J., \& Chereni, A. (2019). Using African Ubuntu Theory in Social Work with Children in Zimbabwe. African Journals of Social Work, 9, 27-34.

Mugumbate, J., \& Chereni, A. (2020). Now the Theory of Ubuntu Has Its Space in Social Work. African Journal of Social Work, 10, 5-17.

Olum, Y. (2004). Modern Management Theories and Practices. Being a Paper Presented at the 15th East African Central Banking Course, Kasarani, 12 July 2004, 1-24.

Rankopo, M. J., \& Osei-Hwedie, K. (2011). Globalization and Culturally Relevant Social Work: African Perspectives of Indigenization. International Journal of Social Work, 54, 137-147. https://doi.org/10.1177\%2F0020872810372367

Ridgeway, C. L., \& Berger, J. (1986). Expectations, Legitimation, and Dominance Behaviour in Task Groups. American Sociological Review, 51, 603-617.

https://doi.org/10.2307/2095487

Robbins, S. P. (2009). Management. Prentice Hall.

Robbins, S. P., \& Coulter, M. (2007). Management (9th ed.). Prentice Hall.

Rubin, A., \& Babbie, E. R. (2011). Research Methods for Social Work. Brooks/Cole.

Ryan, D. (2014). Functions of Management 101-The Importance of the Top 5 Functions.

Saunders, M., Lewis, P., \& Thornhill, A. (2009). Research Methods for Business Students. Pearson Education Limited.

Stonner, J. A. F., Freeman, R. E., \& Gilbert, D. R. (2003). Management. Prentice-Hall.

Yalokwu, P. O. (2006). Fundamentals Management. African Centre for Management and Education. 